\title{
Ajdukiewicz on analyticity
}

\author{
Jan Woleński ${ }^{1}$
}

Published online: 16 February 2016

(C) The Author(s) 2016. This article is published with open access at Springerlink.com

\begin{abstract}
This paper presents the development of Ajdukiewicz's conception of analytic sentences. Starting from his pre-war radical conventionalism, the presentation proceeds to Ajdukiewicz's moderate aposteriorism and, finally, to radical aposteriorism. Various accounts of analyticity by Ajdukiewicz are mentioned and briefly commented on. At the end of the paper, Ajdukiewicz's influence on Polish philosophy in regard to the issue of analyticity is pointed out.
\end{abstract}

Keywords Epistemology - Analytic sentences - Synthetic sentences - A priori - A posteriori $\cdot$ Meaning rules

In the works he published in the interwar period Kazimierz Ajdukiewicz did not use the label 'analytic sentence' (proposition, etc.). On the other hand, we can associate analyticity with his theory of meaning as an essential part of radical conventionalism. According to Ajdukiewicz, (see Ajdukiewicz 1934a, b) the meaning of expressions determines so-called meaning rules (meaning directive). These rules dictate acts of assertion of propositions by the users of a given language. We have three distinct kinds of such directives. Firstly, there are axiomatic meaning rules, which require the unconditional assertion of sentences (I will use the term 'sentence' and 'propositions' as equivalent). For example, an axiomatic rule forces assertion of the sentence ' $a=a$ '. Secondly, if someone asserts the proposition ' $b=a$ ' on the basis of previously asserting the proposition ' $a=b$ ', he or she appeals to a deductive directive. Thirdly, the assertion of the sentence 'London is the capital of the UK' depends on the fact that London is the capital of England and being conscious of that fact. This situation is organized by an empirical meaning rule falling under the scheme 'a sentence $A$ should be asserted in empirical

Jan Woleński

wolenski@if.uj.edu.pl

1 Kraków, Poland 
circumstances $E$ '. In perfect scientific languages (I omit details of their definition), not only does meaning determine meaning rules, but the reverse dependence holds as well: the directives define meaning. In other words, in such languages we have parity between meaning and meaning rules.

A simple way to define analytic sentences in the context of meaning rules consists in saying that they are asserted on the basis of axiomatic and deductive meaning rules. Why did Ajdukiewicz avoid the label 'analytic proposition'? His attitude in this respect seems surprising, because he was very well versed in Kant's philosophy and debates around the foundations of mathematics in the years 1900-1930; the problem of analyticity played a crucial role in both cases. Ajdukiewicz's actual reason to stay away from the term 'analytic proposition' was probably a consequence of his general conventionalist position. Poincaré, the master of conventionalism, did not attach a special importance to analytic sentences. Roughly speaking, to qualify conventions as analytic propositions adds nothing particularly interesting to the way the former function in science. Moreover, Ajdukiewicz thought that the world-picture could always be changed by adopting a new language framework. This point of radical conventionalism is at odds with the view that analytic sentences are stable elements of every language and should be unconditionally protected against abandonment by science.

These remarks about Ajdukiewicz's motives are merely guesses. In fact, to regard sentences as asserted on the basis of axiomatic and deductive rules as analytic appears quite natural. Ajdukiewicz himself supported such treatment in (Ajdukiewicz 1947: 173/174) and in his polemics with Adam Schaff (see Ajdukiewicz 1953: 161). ${ }^{1}$ However, this change came after he had recognized the significance of the problem of analyticity. Anyway, irrespective of whether we qualify sentences asserted via axiomatic and deductive meaning rule as analytic, at least one idea remains constant during Ajdukiewicz's academic career: he always explicitly connected the problem of analyticity with the epistemological question about the sources of knowledge. Perhaps it is significant to some extent that Ajdukiewicz sometimes tried to eliminate the category of empirical meaning rules by reducing them to axiomatic and deductive directives. This move can be interpreted as a step towards a kind of apriorism.

As far as I know, Ajdukiewicz's first substantial appeal to the concept of analyticity appears in (Ajdukiewicz 1946: 12). He writes:

One must admit that logical empiricists did not provide a proof that every a priori proposition has to be analytic (in Kant's sense), and, thereby, that such a proposition is an expression of the linguistic usage. I think, however, that it would not be very difficult to come up with such a proof. A more adequate clarification of the concept of analytic proposition is required to perform this task.

This passage should be carefully interpreted. One possible reading points out that Ajdukiewicz is close to the co-called moderate methodological empiricism (the view defended by logical empiricism), that is, the position according to which

\footnotetext{
${ }^{1}$ Page-references are to translations or reprints, if they are listed in references at the end of this paper.
} 
human knowledge consists of synthetic a posteriori propositions (empirical science) and analytic propositions (logic and mathematics). Consequently, synthetic a priori sentences do not exist. The second reading implies that Ajdukiewicz considers the proof that synthetic apriora do not exist as based on a better elucidation of analyticity, but abstains from deciding whether the analysis based on a new concept of analytic sentence should be regarded as ultimate or even satisfactory to some extent. In any case, looking at the quoted passage from the perspective of Ajdukiewicz's later philosophy, it seems that he was much closer to moderate empiricism in the 1930s.

Ajdukiewicz (1947) offers an interesting classification of possible views concerning the methodological controversy over the sources of knowledge. He distinguishes (see also Chapter 3 in Ajdukiewicz 1949): (a) radical apriorism (methodological rationalism) (Plato); (b) moderate apriorism (methodological rationalism) (Kant); (c) radical aposteriorism (methodological empiricism) (Mill); (d) moderate aposteriorism (methodological empiricism) (logical empiricism). This classification correlates these epistemological standpoints with the kinds of sentences present (legitimate) in knowledge (see also Nowaczyk 1979). Ajdukiewicz uses Kant's division of propositions: analytic (they are always a priori), synthetic a priori, and synthetic a posteriori. Ajdukiewicz explicitly defines analytic sentences (Ajdukiewicz 1973: $173 / 174$ ) as the axioms of the language in question, that is, accepted via axiomatic rules or those which are inferred from the axioms. He adds (1973: 174):

Such a definition of [analytic] sentences seems to be a better expression of the intention which induced Kant to introduce the notion of analytic sentences than his own which, as is well known, can be applied only to affirmative subjectpredicate sentences, and which is, therefore, not general enough. It also seems that the above definition of the term 'analytic sentence' is more in accord with Kant's intentions than the somewhat different definition proposed by Carnap.

It is plausible to think that the definition presented in this passage is the one that Ajdukiewicz had in mind in 1946. Although Ajdukiewicz points out a discord with Carnap (probably taking into account the purely syntactic definition of analyticity in Carnap's Logical Syntax of Language), both philosophers shared the view that analytic sentences require no appeal to experience for their acceptance

The correlation between epistemological views and kinds of sentences present in knowledge is the following:

radical apriorism moderate apriorism

moderate aposteriorism sentences a priori (analytic, synthetic a priori); all kinds of sentences (analytic, synthetic a priori, radical aposteriorism synthetic a posteriori; analytic (logic and mathematics), synthetic a posteriori (empirical science).

This account is very effective. It shows (among other thing) that the real battle between apriorism and aposteriorism concerns synthetic a priori propositions and analytic sentences inside the empiricist camp. Moreover, radical apriorism (in particular, Plato's case) makes a distinction between demonstrative knowledge and intuitive knowledge. In Ajdukiewicz's scheme, the latter finds its proper expression 
in synthetic a priori propositions, but the former in analytic sentences. Ajdukiewicz's own view consisted in a certain compromise between moderate and radical apriorism. On the one hand, he considers the category of analytic sentences as fairly significant for epistemology, but he rejects the view that such sentences have nothing to do with experience. The second point concerns the role of logic in science. For Ajdukiewicz, logical theorems act as auxiliary hypotheses connected with the empirical theories. This means that they are accepted or rejected together with genuine empirical hypotheses. This account explains why analytic sentences, in particular, logical rules, do not require a direct reference to experience for their assertion. However, it does not exclude an indirect appeal to experiential data. Ajdukiewicz formulates a kind of linguistic holism in this view. It bears explicit affinities with Quine's holistic approach to language. The main difference between both philosophers consists in the fact that Quine's view is global (holism applies to the entire language as a unit) and Ajdukiewicz's holism is local, that is, restricted to concrete theories. In other words, experience influences the whole language in Quine's case, but only its fragments in Ajdukiewicz's epistemological analysis. A slightly different approach is offered in Ajdukiewicz (1949). He defines analytic sentences as those explicating the meaning of their constituents and their logical consequences, and this approach is perhaps the closest to moderate empiricism in Carnap's sense (analytic sentences serve as meaning postulates). However, Ajdukiewicz thought that this explanation would be didactically optimal (Ajdukiewicz 1949 was conceived as a rather elementary textbook).

Ajdukiewicz worked on the relation between analytic sentences and experience until the end of his life. He gradually moved towards more radical methodological empiricism (see Ajdukiewicz 1958, 1964b). This evolution also influenced his account of analyticity. In the former paper, he introduced two concepts of analytic sentences given by the definitions: (i) $A$ is an analytic sentence in the semantic sense in a language $\mathbf{L}$ if and only if $A$ is a meaning postulate of $\mathbf{L}$ or $A$ is a logical consequence of such postulates; (ii) $A$ is an analytic sentence in the syntactic sense if and only if $A$ is a logical truth (a truth invariant) under substitution of descriptive (extralogical) constituents occurring in $A$, or it is reducible to logical truth in virtue of the syntactic conventions of $\mathbf{L}$. The second definition is influenced by the Bolzano-Tarski-Quine account of logical truth as being invariant under substitution of extralogical elements in sentences. As far as definition (i) is concerned, Ajdukiewicz probably followed Carnap's idea of meaning postulates and their logical consequences (Ajdukiewicz did not refer to Carnap in his paper). He understood syntactic conventions as rules of transformation of expressions. However, Ajdukiewicz introduced a novelty in his understanding of analyticity as compared with that of logical empiricism. Contrary to Carnap and other representatives of the Vienna Circle, Ajdukiewicz maintained that justification of analytic sentences sometimes requires an appeal to experience. In particular, it can happen that we need to check whether individual constants are not empty. This occurs in the case of the formula (a theorem of first-order logic):

$$
(*) F a \rightarrow \sum x F x
$$


which can be illustrated (Ajdukiewicz's own example) by the following case. Define Polyphemus as the tallest man whose height is over $100 \mathrm{~m}$ (Polyphemus $=$ the tallest man whose height is over $100 \mathrm{~m}$ ). This definition should be regarded as an analytic sentence. Using (*) we easily conclude that there is a person whose height is over $100 \mathrm{~m}$. However, this conclusion is false and derived from the true analytic sentence. The example shows that we sometimes need to check empirical facts (in this case, the height of so defined Polyphemus) in order to justify our inferences. The paper (Ajdukiewicz 1964b) was published posthumously. In a sense, it can be considered as Ajdukiewicz's philosophical last will. He essentially radicalised his earlier empiricism. Returning to his early philosophy of language, Ajdukiewicz outlined a semantic project in which empirical meaning rules function as the only directives regulating the use of language. However, since Ajdukiewicz did not develop this idea, nothing more is known about how this task could be achieved.

How influential was Ajdukiewicz's account of analyticity in Poland? At first, let me note that Ajdukiewicz's views on analyticity provoked some criticism (see Czerwiński 1964). The main argument against Ajdukiewicz points out that it is hard to consider the definition of Polyphemus as the tallest person whose height is over $100 \mathrm{~m}$ as a true analytic sentence. Since every individual constant has a fixed reference according to classical logic, the same concerns Polyphemus. Furthermore, the identity 'Polyphemus $=$ the tallest man whose height is over $100 \mathrm{~m}$ ' does not need to be interpreted as analytic. Since it is false, there is nothing wrong about (*). Disregarding this criticism (its full treatment requires a closer analysis of how analyticity is related to various logics, for instance, to free logic, that is, logic without existential posits), all Polish authors dealing with this problem followed Ajdukiewicz and relativized analytic sentences to a language L. A more concrete influence can be summarized in the following way. Maria Kokoszyńska (see Kokoszyńska 1947) defined analytic sentences as analytic theorems of a language $\mathbf{L}$ or a negation of such a theorem. Roughly speaking, analytic sentences are generated by procedural rules similar to axiomatic and deductive meaning rules in Ajdukiewicz's sense. Borkowski (1966) distinguished three kinds of analytic sentences: (i) in the semantic sense, that is, true in all non-empty domains; (ii) in the syntactic sense, that is, derivable exclusively by logical inference rules; (iii) in the pragmatic sense, that is, asserted by axiomatic and deductive directives. Proposal (i) is a model-theoretic definition, (ii) is essentially Fregean, and (iii) uses concepts introduced by Ajdukiewicz. Przełęcki and Wójcicki (1977) developed the idea of analytic components of synthetic sentences (definitions, in particular) starting from Ajdukiewicz's observation that, in view of the problem of justification, the boundary between analytic and synthetic sentences is not absolutely sharp. Adam Nowaczyk used Ajdukiewicz's distinctions developed in (Ajdukiewicz 1958) in order to show that they offer a new perspective on analysing the old problem of apriorism. My own attempt (see Woleński 2004) continued the aforementioned ideas of Borkowski, but I supplemented his tripartite distinction by adding the categories of absolute and relative analytic sentence. Analytic sentences in the pragmatic sense (they are always relative) are a good area in which one can look for empirical foundations of analyticity. This brief survey shows that Ajdukiewicz's thoughts on the concept of analyticity were fairly productive in Poland. One might 
even speak about a Polish conception of analytic sentences having the following main ingredients: a satisfactory definition of analytic sentences is possible; there are many kinds of analytic propositions; analytic sentences must be relativised to a language or/and perhaps logic; analytic sentences sometimes refer to experience; analytic sentences are not always tautologies; the category of analytic propositions is significant for epistemology.

Open Access This article is distributed under the terms of the Creative Commons Attribution 4.0 International License (http://creativecommons.org/licenses/by/4.0/), which permits unrestricted use, distribution, and reproduction in any medium, provided you give appropriate credit to the original author(s) and the source, provide a link to the Creative Commons license, and indicate if changes were made.

\section{References}

Ajdukiewicz, K. (1934a). Sprache und Sinn, Erkenntnis, IV: 100-138; Eng. tr. in Ajdukiewicz (1979: 35-66).

Ajdukiewicz, K. (1934b). Das Weltbild und die Begriffsapparatur, Erkenntnis, IV: 259-287; Eng. tr. in Ajdukiewicz (1979: 69-87).

Ajdukiewicz, K. (1946). O tzw. neopozytywizmie (On so-called neo-positivism), Myśl współczesna, II: 155-176; reprinted in Ajdukiewicz (1964: 9-33).

Ajdukiewicz, K. (1947). Logika i doświadczenie (Logic and experience), Przeglad filozoficzny, XLIII: 3-22. Eng. tr. in Ajdukiewicz (1979: 165-181).

Ajdukiewicz, K. (1949). Zagadnienia i kierunki filozofii (Warszawa: Czytelnik); Eng. tr., Ajdukiewicz (1973).

Ajdukiewicz, K. (1953). W sprawie artykułu prof. A. Schaffa o moich poglądach filozoficznych (Reply to Professor Schaff's article concerning my philosophical views), Myśl filozoficzna, 2: 292-334; reprinted in Ajdukiewicz (1964: 155-191).

Ajdukiewicz, K. (1958). Le problème du fondement des propositions analytiques, Studia logica, VIII: 259-272; Eng. tr. in Ajdukiewicz (1979: 254-268).

Ajdukiewicz, K. (1964a). Jezyk i poznanie ('Language and Knowledge'), v. II. Warszawa: Państwowe Wydawnictwo Naukowe.

Ajdukiewicz, K. (1964b). Zagadnienie empiryzmu a koncepcja znaczenia (The problem of empiricism and the concept of meaning). In Ajdukiewicz (1964: 388-400); Eng. tr. in Ajdukieweicz (1979: 306-319).

Ajdukiewicz, K. (1973). Problems and theories of philosophy. Cambridge: Cambridge University Press.

Ajdukiewicz, K. (1979). The scientific world perspective and other essays 1931-1965. Dordrecht: D. Reidel.

Borkowski, L. (1966). Deductive foundations and analytic propositions. Studia Logica, XIX, 59-72.

Czerwiński, Z. (1964). Zdania analityczne, logika i doświadczenie (Analytic sentences, logic and experience). In Rozprawy logiczne. Ksiega Pamiatkowa ku czci profesora Kazimierza Ajdukiewicza (Festschrtift in Honor of Professor Kazimierz Ajdukiewicz) (Warszawa: Państwowe Wydawnictwo Naukowe), pp. 23-30.

Kokoszyńska, M. (1947). O różnych rodzajach zdań (On various kinds of sentences'). Przeglad Filozoficzny, XLIII, 22-51.

Nowaczyk, A. (1979). Analyticity and apriority. In J. Pelc (Ed.), Semiotics in Poland (pp. 464-483). Warszawa: PWN - Polish Scientific Publishers.

Przełęcki, M., \& Wójcicki, R. (1977). The problem of analyticity. In M. Przełęcki \& R. Wójcicki (Eds.), Twenty-five years of logical methodology in Poland (pp. 589-614). Warszawa: PWN - Polish Scientific Publishers.

Woleński, J. (2004). Analytic vs. synthetic and a priori vs. a posteriori. In I. Niiniluoto, M. Sintonen, \& J. Woleński (Eds.), Handbook of epistemology (pp. 781-839). Dordrecht: Kluwer. 